DOI: https://doi.org/10.47405/mjssh.v6i8.979

\begin{tabular}{|c|c|}
\hline 4 & Malaysian Journal of Social Sciences and Humanities (MJSSH) \\
\hline $\begin{array}{l}\text { Malaysian Juoural of } \\
\text { Social ccciecces and }\end{array}$ & Volume 6, Issue 8, August 2021 \\
\hline (MJ-sSH) & e-ISSN : 2504-8562 \\
\hline & $\begin{array}{l}\text { Journal home page: } \\
\text { www.msocialsciences.com }\end{array}$ \\
\hline
\end{tabular}

\title{
Struktural Ekosistem dan Tadbir Urus Mahkamah Anak Negeri di Sabah
}

\author{
Rosazman Hussin ${ }^{1,2}$, Johan Johnes ${ }^{1,2}$, Jabil Mapjabili,2, Jeannet Stephen ${ }^{1,3}$, Jurry Foo @ Jurry Bt. F. \\ Michael1,2,4 \\ ${ }^{1}$ Institut Kajian Orang Asal Borneo, Universiti Malaysia Sabah (UMS) \\ ${ }^{2}$ Fakulti Sains Sosial dan Kemanusiaan, Universiti Malaysia Sabah (UMS) \\ ${ }^{3}$ Pusat Penataran Ilmu dan Bahasa, Universiti Malaysia Sabah (UMS) \\ ${ }^{4}$ Pusat Kokurikulum dan Pembangunan Pelajar, Universiti Malaysia Sabah (UMS) \\ Correspondence: Rosazman Hussin (azzs@ums.edu.my)
}

\begin{abstract}
Abstrak
$\overline{\text { Sistem perundangan tradisional dalam kalangan masyarakat orang asal merupakan sebuah peninggalan }}$ unik dari segi sistem kawalan sosial tingkah laku masyarakat serta banyak diamalkan dalam kalangan masyarakat peribumi di seluruh dunia. Mahkamah Anak Negeri di Sabah merupakan institusi kehakiman yang bertanggungjawab dalam menguruskan hal-hal perbicaraan yang berlaku dalam kalangan penduduk orang asal atau yang lebih dikenali sebagai Anak Negeri di negeri ini. Kajian ini dijalankan bertujuan untuk memberi gambaran secara lebih mendalam berkenaan latar belakang ataupun sorotan literatur berkenaan struktural ekosistem dan tadbir urus yang dilaksanakan khususnya di Mahkamah Anak Negeri Sabah. Kajian ini menggunakan kualitatif sebagai metodologi kajian iaitu meruju dan menganalisis sumber-sumber primer dan sekunder dalam menghasilkan dapatan kajian. Antara dapatan kajian yang ditemui adalah penjelasan berkenaan struktural ekosistem Mahkamah Anak Negeri Sabah dan tadbir urus Mahkamah Anak Negeri Sabah pada masa kini. Misalnya, hasil daripada penelitian, didapati bahawa bidang tugas Ketua Kampung adalah agak banyak berbanding bidang tugas yang dipegang oleh perjawatan lain yang terdapat dalam struktur pentadbiran Mahkamah Anak Negeri di Sabah. Oleh itu, penelitian yang lebih menyeluruh dalam struktural ekosistem dan tadbir urus Mahkamah Anak Negeri adalah amat penting untuk memastikan fungsi Mahkamah Anak Negeri Sabah ini dapat dioptimumkan.
\end{abstract}

Kata kunci: Struktural ekosistem, tadbir urus, Mahkamah Anak Negeri Sabah

\section{Structural Ecosystem and Governance of Native Court in Sabah}

\begin{abstract}
The traditional legal system among indigenous peoples is a unique legacy in terms of the social control system of community behavior and is widely practiced among indigenous peoples around the world. The Native Court in Sabah is a judicial institution responsible for managing trial matters that take place among the indigenous population or better known as "Anak Negeri" in Sabah. This study was conducted to provide a more in -depth picture of the background or literature highlights on the structure of the ecosystem and governance implemented especially in the Sabah Native Court. This study uses qualitative as a research methodology that is to refer and analyze primary and secondary sources in producing research findings. Among the findings of the study is an explanation of the structural ecosystem of the Sabah Native Court and the governance of the Sabah Native Court today. For
\end{abstract}


example, as a result of the study, it was found that the duties of the Village Head (Ketua Kampung) is quite a lot compared to the duties held by other positions in the administrative structure of the Native Court in Sabah. Therefore, a more comprehensive study of the ecosystem structure and governance of the Native Court is very important to ensure that the function of the Sabah Native Court can be optimized.

Keywords: Structural Ecosystem, governance, Sabah Native Court

\section{Pengenalan}

Mahkamah Anak Negeri merupakan institusi perundangan yang menguruskan hal ehwal orang asal berdasarkan undang-undang adat. Mahkamah Anak Negeri Sabah merupakan salah satu daripada institusi perundangan yang terdapat di Malaysia. Menurut Pertubuhan Harta Intelek Dunia (WIPO) (2016), adat didefinisikan sebagai sekumpulan aturan, praktik dan kepercayaan yang diterima oleh sekumpulan masyarakat. Malah, Soerjono (1983) menekankan bahawa adat berkait rapat dengan sistem kepercayaan. Muhammad Takari dan Fadlin (2019) menegaskan bahawa adat merupakan inti dalam peradaban atau Tamadun Melayu dan sering dikaitkan dengan bagaimana manusia menguruskan dirinya sendiri, kelompok masyarakat serta hubungan manusia dengan alam sekitar (sama ada alam nyata ataupun alam ghaib) serta hubungan manusia dengan pencipta.

Adat merupakan peraturan yang dilaksanakan (diamalkan) secara turun-temurun dalam sebuah masyarakat sehingga ia menjadi hukum dan peraturan yang harus dipatuhi (Husin Embi et al., 2004). Menurut Theodorson (1964), adat merujuk kepada norma sosial yang menjadi standard moral tingkah laku kumpulan dan masyarakat yang menetapkan bahawa ketidakpatuhan adalah dilarang keras. Menurut beliau, ahli kumpulan atau masyarakat merasakan keterikatan emosional terhadap kebiasaan dan pemeliharaan adat adalah penting untuk kesejahteraan masyarakat.

Oleh itu, untuk memahami dengan baik fungsi Mahkamah Anak Negeri di Sabah, maka penelitian terhadap struktural ekosistem dan tadbir urus dalam pentadbirannya perlulah diambil kira. Struktural ekosistem yang dimaksudkan adalah interaksi atau hubung kait persekitaran dalam Mahkamah Anak Negeri yang secara khusus meneliti perjawatan dan pembahagian tugas dalam sistem Mahkamah Anak Negeri. Manakala, penelitian berkenaan tadbir urus pula berfokus kepada penelitian terhadap proses urusan harian anak negeri yang datang ke Mahkamah Anak Negeri di kawasan mereka. Kajian ini turut membincangkan secara spesifik sorotan literatur berkenaan apakah itu Mahkamah Anak Negeri Sabah, siapakah anak negeri Sabah dan sejarah struktur pentadbiran Mahkamah Anak Negeri pada zaman pemerintahan British di Sabah.

\section{Sorotan Literatur}

Pada umumnya, undang-undang adat merupakan identiti yang penting dalam kronologi tamadun manusia di Sabah. Menurut Azlizan dan Salbiya (2020), dalam konteks anak negeri di Sabah, sejarah mengenai undang-undang adat merupakan satu perkara penting bagi Sabah. Malahan, sebelum Sabah ditadbir oleh British North Borneo Chartered Company (BNBCC) pada tahun 1881, komuniti anak negeri di Sabah telah mempunyai sistem perundangan yang tersendiri yang diwarisi secara turuntemurun. Sistem kehakiman yang digunakan pada masa tersebut turut menyerupai sistem dalam Mahkamah Anak Negeri yang ada pada hari ini (Azlizan \& Salbiya, 2020). Pada ketika itu, penggunaan undang-undang adat dalam kalangan anak negeri Sabah adalah bersifat tidak formal dan diwarisi secara lisan sahaja daripada generasi yang terdahulu.

Mahkamah Anak Negeri yang ada di Sabah pada hari ini adalah ditadbir berdasarkan Enakmen Mahkamah Anak Negeri (EMAN) 1992. Terdapat tiga peringkat mahkamah yang terdapat dalam sistem Mahkamah Anak Negeri di Sabah menurut EMAN 1992. Tiga peringkat tersebut adalah Mahkamah Anak Negeri, Mahkamah Anak Negeri Daerah dan Mahkamah Rayuan Anak Negeri. 
Berdasarkan Seksyen 3, 4 dan 5 EMAN 1992, hierarki Mahkamah Anak Negeri di Sabah boleh dijelaskan seperti pada Rajah 1.

Rajah 1: Hierarki Mahkamah Anak Negeri di Sabah

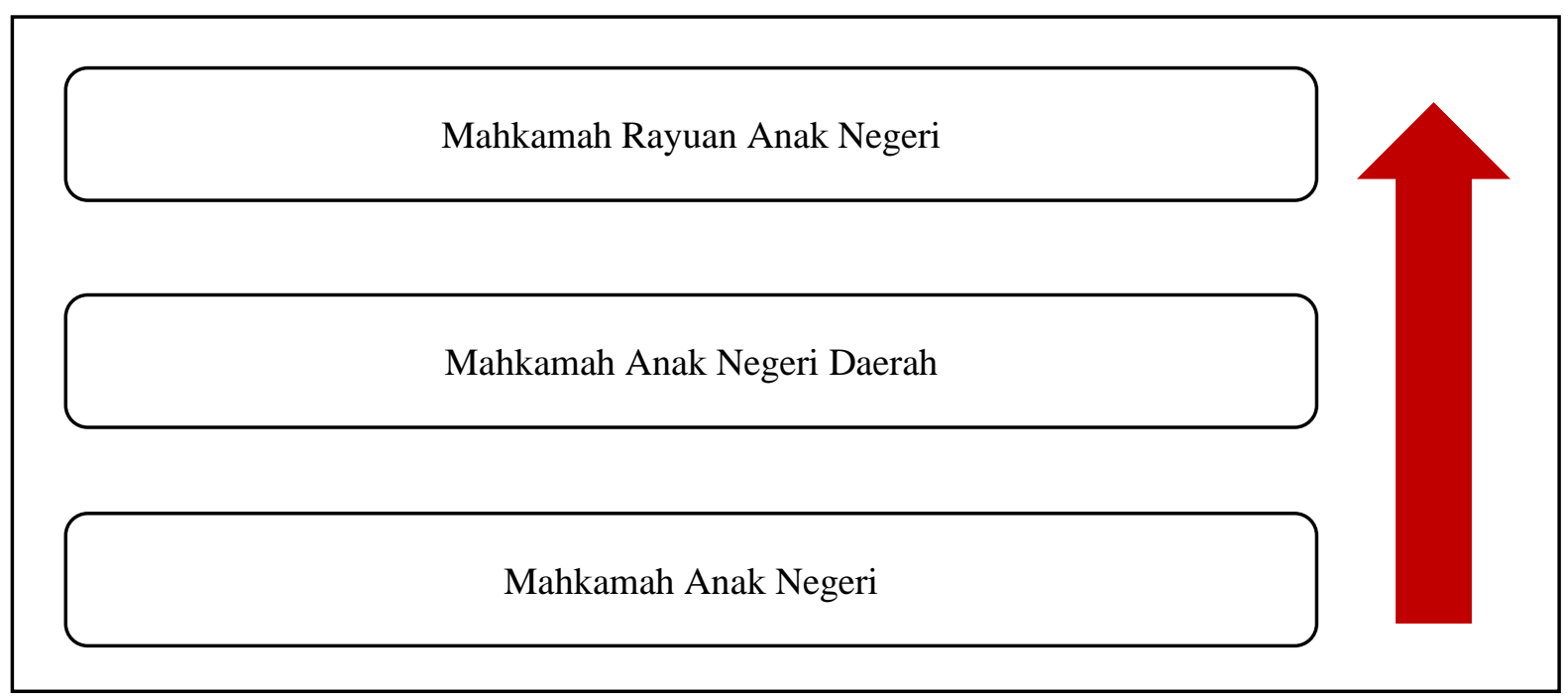

Sumber: Yusri (1998)

Seksyen 3(1\&2) menjelaskan bahawa penubuhan Mahkamah Anak Negeri adalah seperti berikut:

(1) Yang di-Pertua Negeri boleh, melalui pemberitahuan dalam warta, menubuhkan Mahkamah-mahkamah Anak Negeri di mana-mana tempat yang disifatkannya patut, dan boleh menetapkan wilayah bidang kuasa mahkamah-mahkamah itu.

(2) Mahkamah Anak Negeri hendaklah terdiri daripada tiga orang ahli yang adalah Ketua Anak Negeri atau Ketua Kampung yang bermastautin dalam wilayah bidang kuasa Mahkamah Anak Negeri itu dan diberi kuasa dengan sempurna oleh Setiausaha Kerajaan Negeri bagi menjalankan penghukuman di mahkamah itu dan salah seorang daripada mereka hendaklah menjadi ketua yang hendaklah dipilih daripada kalangan mereka:

Dengan syarat bahawa tiada Ketua Anak Negeri atau Ketua Kampung boleh duduk sebagai ahli Mahkamah Anak Negeri dalam perbicaraan apa-apa perkara yang dia mempunyai sesuatu kepentingan peribadi.

Dengan syarat selanjutnya bahawa Setiausaha Kerajaan Negeri boleh, jika difikirkan perlu, memberi kuasa kepada mana-mana Ketua Daerah, Ketua Anak Negeri atau Ketua Kampung bagi menjalankan penghukuman di mana-mana Mahkamah Anak Negeri.

Seksyen 3(1\&2) Enakmen Mahkamah Anak Negeri 1992

Seterusnya adalah penubuhan Mahkamah Anak Negeri Daerah. Seksyen 4(1\&2) menegaskan bahawa penubuhan Mahkamah Anak Negeri Daerah adalah seperti berikut:

(1)Yang di-Pertua Negeri boleh, melalui pemberitahuan dalam warta, menubuhkan Mahkamah Anak Negeri Daerah bagi setiap daerah di Negeri ini yang hendaklah mempunyai bidang kuasa dalam daerah yang baginya mahkamah itu ditubuhkan.

(2) Mahkamah Anak Negeri Daerah hendaklah terdiri daripada Pegawai Daerah bagi daerah itu sebagai ketua dan dua orang ahli 
DOI: https://doi.org/10.47405/mjssh.v6i8.979

lain yang adalah Ketua Daerah atau Ketua Anak Negeri yang bermastautin dalam daerah itu, yang diberi kuasa dengan sempurna oleh Setiausaha Kerajaan Negeri bagi menjalankan penghukuman di mahkamah itu:

Dengan syarat bahawa tiada Ketua Daerah atau Ketua Anak Negeri boleh duduk sebagai ahli Mahkamah AnaK Negeri Daerah dalam perbicaraan sesuatu rayuan tentang apa-apa perkara yang dia mempunyai apa-apa kepentingan peribadi atau jika dia adalah ahli Mahkamah Anak Negeri yang darinya rayuan itu dibuat.

Seksyen 4(1\&2) Enakmen Mahkamah Anak Negeri 1992

Peringkat tertinggi dalam perbicaraan Mahkamah Anak Negeri adalah di Mahkamah Rayuan Anak Negeri. Menurut Seksyen 5(1\&2) EMAN 1992, penubuhan Mahkamah Rayuan Anak Negeri adalah seperti berikut:

(1)Yang di-Pertua Negeri boleh, melalui pemberitahuan dalam warta, menubuhkan Mahkamah Rayuan Anak Negeri bagi Negeri ini yang hendaklah mempunyai bidang kuasa di seluruh Negeri.

(2) Mahkamah Rayuan Anak Negeri hendaklah terdiri daripada seorang Hakim sebagai Presiden, dan dua orang ahli lain yang adalah Ketua Daerah atau Ketua Anak Negeri yang hendaklah dilantik oleh Menteri sebagai ahli mahkamah itu:

Dengan syarat bahawa tiada Ketua Daerah atau Ketua Anak Negeri boleh duduk sebagai ahli Mahkamah Rayuan Anak Negeri dalam perbicaraan sesuatu rayuan tentang apa-apa perkara yang dia mempunyai apa-apa kepentingan peribadi atau jika dia adalah ahli Mahkamah Anak Negeri atau Mahkamah Anak Negeri Daerah yang darinya rayuan itu dibuat.

\section{Seksyen 5(1\&2) Enakmen Mahkamah Anak Negeri 1992}

Berdasarkan Seksyen 6 EMAN 1992, terdapat 15 perkara yang dimaktubkan sebagai bidang kuasa dan kuasa Mahkamah Anak Negeri. Antara bidang kuasa tersebut termasuklah perbicaraan berkenaan pelanggaran adat, urusan perkahwinan, urusan pewarisan berwasiat atau tak berwasiat dan urusan pengambilan anak angkat. Walau bagaimanapun, seperti yang dinyatakan dalam Seksyen 9 EMAN 1992, Mahkamah Anak Negeri tidak boleh mempunyai bidang kuasa berkenaan dengan apa-apa kuasa atau perkara dalam bidang kuasa Mahkamah Syariah atau Mahkamah Sivil. Namun demikian, walaupun dinyatakan dalam EMAN 1992 bahawa Mahkamah Anak Negeri tidak boleh mempunyai bidang kuasa yang bertindih dengan Mahkamah Syariah dan Mahkamah Sivil, masih terdapat beberapa bidang kuasa bertindih di antara ketiga-tiga institusi kehakiman ini (Pg Ismail et al., 2020).

Kajian oleh Pg Ismail et al. (2020) menegaskan bahawa daripada 55 undang-undang perlanggaran adat yang telah digubal melalui Kaedah-Kaedah Mahkamah Anak Negeri (Undang-Undang Adat Anak Negeri) 1995, terdapat 10 peruntukan kaedah yang bertindih dengan kesalahan jenayah syariah, 17 peruntukan kaedah pelanggaran adat yang bertindih dengan peruntukan Kanun Keseksaan dan empat kaedah yang bertindih dengan kedua-dua Mahkamah Syariah dan Mahkamah Sivil. Jadual 1 menunjukkan senarai pelanggaran adat yang mempunyai peruntukan yang bertindih dengan peruntukan kesalahan Jenayah Syariah dan Kanun Keseksaan. 
Jadual 1: Senarai Pelanggaran Adat dalam Undang-undang Adat Anak Negeri

Mahkamah Anak Negeri
Kaedah 4: Menyebabkan kecederaan
Kaedah 5: Ancaman
Kaedah 6: Bangkitan marah
Kaedah 8: Perbuatan sumbang kadim
(adat sumbang)
Kaedah 9: Persetubuhan di antara
sanak saudara
Kaedah 10:
Persetubuhan haram di antara orang-
orang yang belum berkahwin
(mianu-anu)
Kaedah 11: Persetubuhan haram di
ladang atau sawah
Kaedah 13: Penamatan pertunangan
Kaedah 15: Persetubuhan haram oleh
orang yang bertunang
Kaedah 20: Perkahwinan bigami atau
poligami
Kaedah 21: Memikat anak dara
orang lain

Kaedah 24: Menggali kubur

Kaedah 25: Membakar kubur tanpa sebab munasabah

Kaedah 26: Membakar kubur dengan tanpa sengaja

Kaedah 27: Kerosakan pada kubur

Kaedah 28: Gangguan kepada kubur

Kaedah 33: Serangan lucah

Kaedah 34: Pendedahan lucah

Kaedah 35: Perkataan, bunyi atau isyarat lucah

Kaedah 36: Perkataan atau isyarat memfitnah

Kaedah 37: Menyebar kabar angin

Kaedah 40: Pencemaran sumber air

Kaedah 48: Tanggungan terhadap kerosakan oleh binatang

Mahkamah Syariah

Tiada

Tiada

Tiada

Seksyen 78 EKJS 1995:

Perbuatan sumbang

Seksyen 78 EKJS 1995:

Perbuatan sumbang

Seksyen 80 EKJS 1995:

Persetubuhan haram

Seksyen 80 EKJS 1995:

Persetubuhan haram

Seksyen 67 EKJS 1995: Mungkir tunangan

Seksyen 80 EKJS 1995:

Persetubuhan haram

Tiada

Seksyen 87: melarikan anak dara orang

Tiada

Tiada

Tiada

Tiada

Tiada

Tiada

Tiada

Seksyen 100: Mengacau

Seksyen 66 EKJS 1995:

Fitnah

Seksyen 66 EKJS 1995:

Fitnah

Tiada

Tiada
Mahkamah Sivil

Seksyen 321 Kanun Keseksaan:

Dengan sengaja menyebabkan cedera Seksyen 503 Kanun Keseksaan:

Kesalahan menakutkan secara jenayah Seksyen 504 Kanun Keseksaan:

Dengan sengaja mengaibkan dengan niat hendak membangkitkan pecah

keamanan

Seksyen 376A Kanun Keseksaan: Sumbang mahram

Seksyen 376A Kanun Keseksaan: Sumbang mahram

Tiada

Tiada

Tiada

Tiada

Seksyen 494 Kanun Keseksaan: Bigami

Tiada

Seksyen 297 Kanun Keseksaan: Pencerobohan di tempat-tempat perkuburan

Seksyen 297 Kanun Keseksaan:

Pencerobohan di tempat-tempat perkuburan

Seksyen 297 Kanun Keseksaan:

Pencerobohan di tempat-tempat perkuburan

Seksyen 297 Kanun Keseksaan:

Pencerobohan di tempat-tempat perkuburan

Seksyen 297 Kanun Keseksaan:

Pencerobohan di tempat-tempat perkuburan

Seksyen 377D Kanun Keseksaan: Melanggar kesopanan

Seksyen 377D Kanun Keseksaan: Melanggar kesopanan

Tiada

Seksyen 499 Kanun Keseksaan: Fitnah

Seksyen 499 Kanun Keseksaan: Fitnah

Seksyen 277 Kanun Keseksaan:

Mengotorkan air sesuatu mata air atau

kolam air awam

Seksyen 289 Kanun Keseksaan: Kecuaian berkenaan dengan haiwan

Sumber: Diubah suai daripada Pg Ismail et al. (2020), Kaedah Mahkamah Anak Negeri (Undang-Undang Adat Anak Negeri) 1995, Enakmen Kesalahan Jenayah Syariah (Sabah) 1995, Enakmen Undang-Undang Keluarga Islam 1996 dan 2004 dan Kanun Keseksaan. 


\section{Siapakah Anak Negeri Sabah?}

Menurut Kamus Dewan Edisi Keempat (2005), Anak Negeri merujuk kepada penduduk asli sesuatu tempat ataupun bumiputera. Berdasarkan perlembagaan persekutuan, semua anak negeri dianggap bumiputera Malaysia namun bukan semua bumiputera dianggap anak negeri (Berita Harian, 9 Februari 2019). Pg Ismail et al. (2018) menegaskan bahawa anak negeri merupakan istilah yang digunakan secara meluas bagi merujuk bumiputera Sabah. Justeru, agensi kerajaan yang mentadbir hal ehwal bumiputera Sabah dinamakan dengan 'Anak Negeri' seperti Mahkamah Anak Negeri, Pejabat Hal Ehwal Anak Negeri Sabah dan Majlis Hal Ehwal Anak Negeri Sabah. Penggunaan istilah anak negeri ini turut diaplikasikan dalam aspek perundangan bagi semua terjemahan perkataan 'native' dalam undang-undang negeri.

Seksyen 2 (1) Ordinan Tafsiran (Definisi Anak Negeri) 1952 mentakrifkan istilah 'anak negeri' di Sabah sebagai makna sama ada;

(a) mana-mana orang yang kedua ibu bapanya adalah atau merupakan anggota orang yang berasal dari Sabah; atau

(b) mana-mana orang yang biasanya menetap di Sabah dan menjadi dan hidup sebagai anggota komuniti asal, sekurang-kurangnya orang tua atau nenek moyangnya adalah atau berasal dari arti perenggan (a); atau

(c) mana-mana orang yang biasanya menetap di Sabah, adalah anggota Suluk, Kagayan, Simonol, Sibutu atau Ubian atau orang-orang yang berasal dari Negeri Sarawak atau Negeri Brunei, telah tinggal sebagai dan menjadi anggota dari komuniti pribumi untuk jangka masa berterusan tiga tahun sebelum tarikh tuntutannya sebagai orang asli, mempunyai watak yang baik sepanjang tempoh itu dan yang tinggal di Sabah tidak terhad di bawah mana-mana peruntukan Akta Imigresen, 1959/63; atau

(d) mana-mana orang yang biasanya bermastautin di Sabah, adalah anggota masyarakat pribumi Republik Indonesia atau kumpulan pulau Sulu di Kepulauan Filipina atau Negeri-negeri Malaya atau Republik Singapura, telah hidup seperti dan seorang anggota komuniti asli untuk jangka masa berterusan lima tahun tepat sebelum tarikh tuntutannya sebagai orang asli, mempunyai watak yang baik sepanjang tempoh itu dan yang tinggal di Sabah tidak terhad di bawah manamana peruntukan Akta Imigresen , 1959/63.

\section{Sejarah Struktur Pentadbiran Mahkamah Anak Negeri Pada Zaman Pemerintahan British di Sabah}

Atas dasar tanggungjawab semasa pentadbiran British di Sabah, Mahkamah Anak Negeri telah diformalisasikan sebagai badan kehakiman rasmi bermula pada tahun 1913 (NBCA 806, 1913). Malah, menurut Sharifah (1995), BNBCC memperbaharui undang-undang dalam MAN agar undang-undang adat ini boleh dijadikan sebagai satu aturan yang bersistem. Walau bagaimanapun, pendudukan Jepun pada tahun 1942-1945 di Sabah telah menghentikan fungsi Mahkamah Anak Negeri dalam mengendalikan kes-kes berkaitan anak negeri Sabah (Azlizan \& Salbiya, 2020). Peranan dan pentadbiran Mahkamah Anak Negeri di Sabah telah dikembalikan dan diurus tadbir secara lebih sistematik oleh Kerajaan British pada tahun 1946-1963 melalui penggubalan Ordinan Mahkamah Anak Negeri 1953.

Menurut Azlizan dan Salbiya (2020), penubuhan Mahkamah Anak Negeri di Sabah ini turut dipengaruhi oleh pengaruh undang-undang adat, menjimatkan kos pentadbiran BNBCC, Piagam Diraja 1881, mengelakkan penentangan penduduk tempatan dan disebabkan oleh pertambahan populasi penduduk di Sabah. Oleh itu, walaupun pentadbiran British di Sabah mengekalkan corak 
DOI: https://doi.org/10.47405/mjssh.v6i8.979

pentadbiran sedia ada di negeri ini, namun terdapat beberapa rombakan terutamanya dalam institusi pentadbiran peribumi (Mosli, 2009). Perjawatan dalam pentadbiran yang melibatkan pemimpin tempatan adalah agak kurang. Pentadbiran di Sabah diketuai oleh seorang gabenor dan dibantu oleh pesuruhjaya tanah.

Semasa pemerintahan British pada tahun 1946-1963, Sabah dibahagikan kepada tiga residensi iaitu Residensi Pantai Barat, Pantai Timur serta Labuan dan Pedalaman (Whelan, 1970). Setiap residensi ini diwakili oleh residen yang bertanggungjawab dalam soal pentadbiran wilayah yang telah ditetapkan. Organisasi pentadbiran ini seterusnya diteruskan di peringkat yang lebih kecil iaitu melibatkan pegawai daerah, penolong pegawai daerah, ketua anak negeri dan ketua kampung. Dari segi struktur organisasi pentadbiran tanah, gabenor dan pesuruhjaya tanah bertanggungjawab dalam menggubal dasar dan peraturan tanah di Sabah pada ketika itu. Residen bertanggungjawab untuk menghantar laporan bulanan, memberi komen dan pendapat kepada pesuruhjaya tanah. Manakala, pegawai daerah pula mempunyai hubungan interaksi secara terus kepada ketua kampung untuk menyalurkan maklumat tentang penduduk kampung kepada pihak atasan. Rajah 2 menunjukkan struktur organisasi pentadbiran yang melibatkan penduduk tempatan semasa pemerintahan British di Sabah.

Rajah 2: Struktur organisasi pentadbiran British di Sabah pada tahun 1946-1963

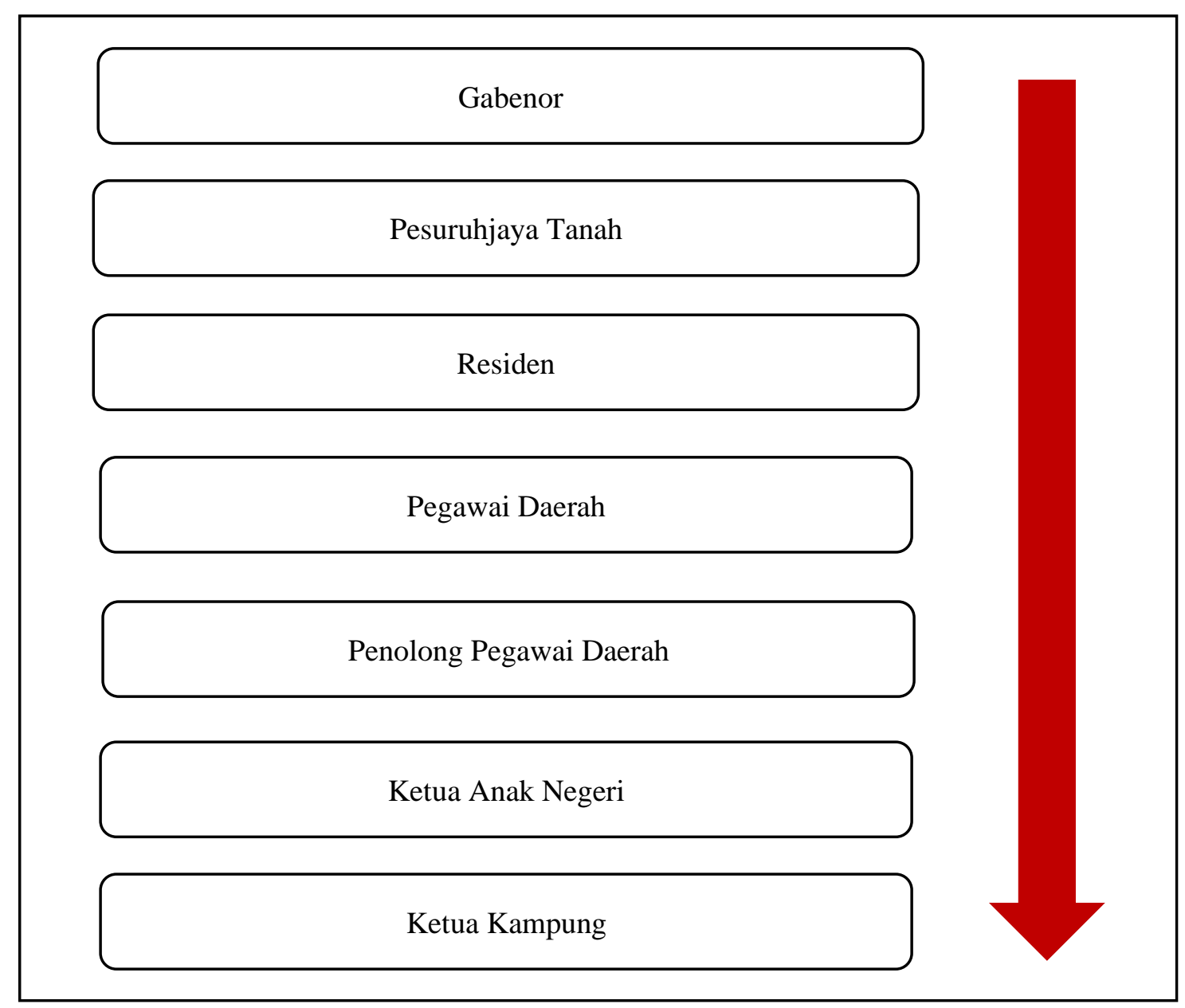

Sumber: Diubahsuai daripada Mosli (2018)

\section{Metod Kajian}

Metodologi kajian yang digunakan adalah kaedah kualitatif iaitu analisis ke atas sumber-sumber primer dan sekunder. Sumber primer yang digunakan ini mempunyai peranan yang penting dalam penyelidikan berkenaan Mahkamah Anak Negeri yang terdapat di Sabah. Pemungutan data dalam kajian ini turut mengambil kira aspek kepustakaan yang melibatkan penelitian dan penafsiran terhadap 
sumber-sumber yang diperoleh oleh pengkaji. Antara sumber yang dirujuk oleh pengkaji adalah Enakmen Mahkamah Anak Negeri 1992, artikel dalam jurnal, bab dalam buku dan akhbar.

\section{Hasil Kajian}

Perbincangan berkenaan hasil kajian dalam kajian ini adalah berfokus kepada penelitian terhadap struktural ekosistem Mahkamah Anak Negeri Sabah dan tadbir urus Mahkamah Anak Negeri Sabah pada masa kini berdasarkan bukti kajian lepas dan penyelidikan pengkaji.

\section{Struktural Ekosistem Mahkamah Anak Negeri Sabah pada Masa Kini}

Dalam sesebuah perbicaraan Mahkamah Anak Negeri di Sabah, undang-undang yang digunakan adalah bergantung terhadap udang-undang adat pihak yang terlibat dalam perbicaraan tersebut. Misalnya, sekiranya kes yang dilaporkan berlaku di kawasan yang mempunyai majoriti etnik Rungus, maka undang-undang adat yang digunakan adalah undang-undang adat etnik Rungus. Struktur Mahkamah Anak Negeri lebih spesifik dalam perjawatan di peringkat Mahkamah Anak Negeri Daerah yang terbahagi kepada empat jawatan utama. Pada peringkat paling bawah, MAN dipengerusikan oleh Ketua Anak Negeri (KAN) dibantu oleh dua Ketua Kampung. Seterusnya Mahkamah Anak Negeri Daerah yang dipengerusikan oleh Ketua Daerah (KD/OKK) dengan bantuan dua orang KAN. Rajah 3 menunjukkan peringkat struktur organisasi dalam Mahkamah Anak Negeri Sabah.

Rajah 3: Struktur organisasi Mahkamah Anak Negeri pada masa kini

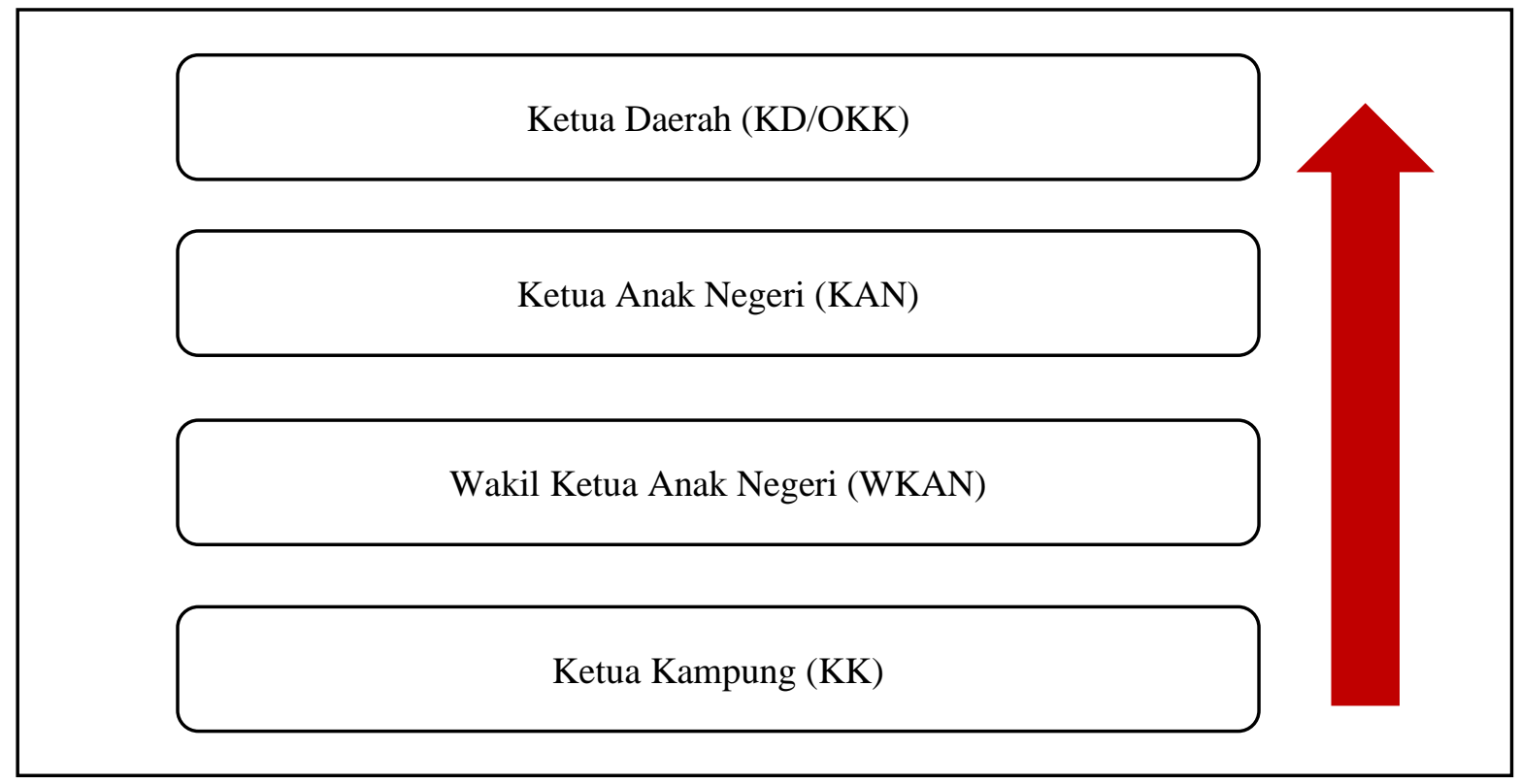

Sumber: Yusri (1998).

Setiap individu yang terdapat dalam struktur organisasi Mahkamah Anak Negeri mempunyai bidang tugas khusus. Misalnya, Ketua Daerah (OKK) merupakan pegawai kerajaan yang berperanan sebagai ketua kepada semua pemimpin masyarakat anak negeri yang terdapat dalam sesebuah daerah berkenaan (Yusri, 1998). Pemimpin-pemimpin yang dimaksudkan adalah Ketua Anak Negeri, Wakil Ketua Anak Negeri dan Ketua Kampung yang mewakili kampung-kampung dan suku-suku kaum yang berbagai. Oleh itu, bahagian ini membincangkan dengan lebih terperinci berkenaan bidang tugas bagi setiap jawatan seperti pada Jadual 2. 
Jadual 2: Bidang Tugas dalam Struktural Ekosistem Mahkamah Anak Negeri di Sabah

\begin{tabular}{|c|c|c|c|}
\hline Ketua Daerah (KD/OKK) & Ketua Anak Negeri (KAN) & Wakil Ketua Anak Negeri (WKAN) & Ketua Kampung (KK) \\
\hline $\begin{array}{l}\text { Memberi panduan dan mengawasi } \\
\text { setiap pekerjanya. }\end{array}$ & $\begin{array}{l}\text { Menjalankan tugas-tugas pentadbiran } \\
\text { dan juga amalan undang-undang adat } \\
\text { negeri serta perkhidmatan Wakil Ketua } \\
\text { Anak Negeri serta Ketua Kampung. }\end{array}$ & $\begin{array}{l}\text { Mengawasi beberapa orang Ketua } \\
\text { Kampung atau beberapa buah } \\
\text { kampung. }\end{array}$ & Ketua masyarakat \\
\hline $\begin{array}{l}\text { Membicarakan dan menyelesaikan } \\
\text { kes-kes yang melibatkan anak negeri. }\end{array}$ & $\begin{array}{l}\text { Bertanggungjawab dalam membantu } \\
\text { Ketua Daerah meningkatkan mutu } \\
\text { perkhidmatan Wakil Ketua Anak Negeri } \\
\text { dan Ketua Kampung mengenai } \\
\text { kepimpinan dan undang-undang adat } \\
\text { anak negeri. }\end{array}$ & $\begin{array}{l}\text { Memberi maklumat adat yang } \\
\text { diamalkan oleh suku kaumnya apabila } \\
\text { dikehendaki oleh Ketua Daerah dan } \\
\text { Ketua Anak Negeri. }\end{array}$ & Ketua hal ehwal adat \\
\hline $\begin{array}{l}\text { Menyedia dan membahagikan tugas- } \\
\text { tugas Mahkamah Anak Negeri } \\
\text { kepada semua Ketua Anak Negeri, } \\
\text { Wakil Ketua Anak Negeri dan Ketua } \\
\text { Kampung. }\end{array}$ & $\begin{array}{l}\text { Membicarakan dan menyelesaikan kes- } \\
\text { kes yang melibatkan anak negeri. }\end{array}$ & $\begin{array}{l}\text { Membantu Ketua Daerah dan Ketua } \\
\text { Anak Negeri dalam sesuatu } \\
\text { perbicaraan anak negeri yang } \\
\text { melibatkan di bawah jagaannya } \\
\text { sekiranya belum ada pengganti Ketua } \\
\text { Kampung atas sebab meninggal dunia } \\
\text { atau disebabkan sebab-sebab lain. }\end{array}$ & Hakim di peringkat kampung \\
\hline \multirow[t]{2}{*}{$\begin{array}{l}\text { Menjalankan tugas-tugas yang diarah } \\
\text { oleh Timbalan Presiden Majlis } \\
\text { Perbandaran atau Pegawai Daerah } \\
\text { dari semasa ke semasa. }\end{array}$} & $\begin{array}{l}\text { Menjalankan tugas-tugas yang } \\
\text { diarahkan oleh Timbalan Presiden } \\
\text { Majlis Daerah dari semasa ke semasa. }\end{array}$ & $\begin{array}{l}\text { Menjalankan tugas-tugas yang } \\
\text { diarahkan oleh Timbalan Presiden } \\
\text { Majlis Perbandaran atau Pegawai } \\
\text { Daerah dari semasa ke semasa. }\end{array}$ & $\begin{array}{l}\text { Menjaga ketenteraman } \\
\text { masyarakat }\end{array}$ \\
\hline & & & $\begin{array}{l}\text { Menjalankan tugas pentadbiran } \\
\text { Merangsang ekonomi penduduk } \\
\text { kampung }\end{array}$ \\
\hline
\end{tabular}




\section{Tadbir Urus Mahkamah Anak Negeri Sabah pada Masa Kini}

Menurut kamus pelajar edisi kedua (2015), tadbir urus merujuk kepada cara atau sistem mentadbir, mengurus mengawal selia sesebuah dasar, fungsi atau perjalanan sesebuah perbadanan, syarikat dan sebagainya. Tadbir urus di Mahkamah Anak Negeri boleh dibahagikan kepada dua peringkat tadbir urus yang utama iaitu tadbir urus di peringkat kampung dan tadbir urus di premis bangunan Mahkamah Anak Negeri atau Mahkamah Anak Negeri Daerah yang terlibat. Tadbir urus di peringkat kampung lazimnya melibatkan urusan penduduk kampung sama ada membuat laporan ataupun apaapa urusan penting yang memerlukan penglibatan Ketua Kampung. Manakala, tadbir urus di peringkat mahkamah pula melibatkan urusan penduduk kampung untuk meminta pengesahan, menghadiri perbicaraan serta melibatkan pembahagian tugas dan masa bekerja dalam kalangan kakitangan yang terdapat dalam Mahkamah Anak Negeri terutamanya Keta Daerah, Ketua Anak Negeri dan Wakil Ketua Anak Negeri.

Secara amnya, tidak terdapat satu panduan khas berkenaan tadbir urus dalam pentadbiran Mahkamah Anak Negeri di Sabah. Setiap Mahkamah Anak Negeri mempunyai cara yang berlainan dalam menguruskan fail dan pembahagian tugas harian dalam kalangan mereka. Walau bagaimanapun, terdapat persamaan dalam tadbir urus harian di antara mahkamah ini. Ciri tadbir urus tersebut boleh dijelaskan melalui dua jenis tadbir urus utama iaitu tadbir urus di peringkat kampung dan tadbir urus di premis Mahkamah Anak Negeri.

\section{Tadbir urus di peringkat kampung}

Tempoh masa berurusan di peringkat kampung adalah tidak ditetapkan, sebarang urusan kecemasan ataupun keperluan yang mendesak dalam kalangan penduduk kampung boleh dirujuk secara terus 24 jam kepada Ketua Kampung. Walau bagaimanapun, Ketua Kampung boleh menetapkan jadual tertentu bagi urusan-urusan harian seperti untuk mendapatkan tandatangan pengesahan bagi dokumendokumen tertentu. Urusan di peringkat kampung adalah bersifat tidak formal yang tidak terikat dengan keperluan untuk mematuhi kod pemakaian tertentu. Penduduk kampung boleh berurusan dengan Ketua Kampung dengan pakaian harian mereka. Malah, dalam banyak urusan tadbir urus di peringkat kampung, tiada cas perkhidmatan yang dikenakan oleh setiap penduduk yang datang untuk meminta nasihat ataupun merujuk berkenaan undang-undang adat kepada Ketua Kampung.

Manakala, bagi urusan fail pula, tidak terdapat satu sistem khas yang dibangunkan atau disediakan oleh pihak Mahkamah Anak Negeri. Atas inisiatif sendiri, Ketua Kampung menyediakan fail untuk merekodkan kes-kes ataupun aduan yang diterima daripada penduduk. Malah, terdapat ketua kampung yang menyediakan bilik atau bangunan khas untuk tempat perjumpaan bagi urusan penduduk kampung mereka. Sehubungan itu, tempat perbicaraan bagi kes-kes yang diuruskan oleh Ketua Kampung juga adalah tidak disediakan secara khusus. Perbicaraan di peringkat kampung biasanya dilakukan di rumah penduduk yang terlibat dalam satu-satu kes tersebut, di rumah Ketua Kampung, di balai raya ataupun di dewan serba guna kampung. Perbicaraan di peringkat kampung diketuai oleh Ketua Kampung dan dibantu oleh orang tua-tua yang mempunyai pengetahuan dan pengalaman yang lebih mendalam berkenaan sesuatu undang-undang adat tersebut.

\section{Tadbir urus di Mahkamah Anak Negeri}

Di Mahkamah Anak Negeri, tadbir urus dijalankan mengikut waktu pejabat di jabatan kerajaan. Premis akan beroperasi seawal jam 8.00 pagi sehingga 9.00 pagi dan ditutup pada sekitar jam 4.30 petang sehingga jam 5.00 petang. Premis Mahkamah Anak Negeri juga hanya beroperasi pada hari bekerja sahaja dan ditutup pada hujung minggu melainkan ada urusan tertentu, maka mahkamah akan beroperasi setengah hari bermula jam 8.00 pagi sehingga jam 12.00 tengah hari. Berbeza dengan urusan di peringkat kampung, etika pemakaian ditetapkan di premis Mahkamah Anak Negeri. misalnya, bagi Mahkamah Anak Negeri Daerah Penampang, etika pemakaian adalah seperti berikut:

i. Lelaki tidak dibenarkan memakai kemeja-t tidak berkolar, seluar pendek, selipar, jeans koyak, topi

ii. Perempuan tidak dibenarkan memakai kemeja-t tanpa lengan, skirt pendek (atas paras lutut), selipar, jeans koyak, topi 
DOI: $\operatorname{xxxxxxx}$

Manakala, bagi pelawat yang datang ke Mahkamah Anak Negeri, mereka adalah dilarang untuk berpakaian tidak sopan/mendedahkan tubuh ataupun memakai pakaian yang menjolok mata. Seterusnya adalah sistem fail di Mahkamah Anak Negeri. Berbanding tadbir urus di peringkat kampung, sistem pemfailan aduan atau kes di Mahkamah Anak Negeri adalah lebih teratur. Terdapat pegawai yang terdiri daripada KAN dan WKAN yang ditugaskan untuk menguruskan fail-fail yang terdapat di Mahkamah Anak Negeri dan perbicaraan yang dilakukan adalah khas di bilik perbicaraan yang terdapat di premis mahkamah. Walau bagaimanapun, sesetengah perkhidmatan yang disediakan di Mahkamah Anak Negeri dikenakan bayaran. Misalnya, sewaan pelamin bagi pasangan yang memilih untuk berkahwin di premis Mahkamah Anak Negeri. Hal ini disebabkan oleh keperluan menampung kos penyelenggaraan bangunan seperti pembelian set pelamin dan perkakas pembersihan.

\section{Kesimpulan}

Tuntasnya, penelitian secara holistik dalam struktural ekosistem dan tadbir urus Mahkamah Anak Negeri adalah amat penting untuk membantu dalam peningkatan kualiti dan kepercayaan masyarakat di Sabah untuk berurusan di mahkamah ini. Perhatian terhadap pemantapan struktural ekosistem Mahkamah Anak Negeri di Sabah perlulah diperkukuhkan dengan menambah baik sistem lantikan dan meletakkan kelayakan akademik sebagai kayu ukur dalam melantik perjawatan di Mahkamah Anak Negeri. Tambahan lagi, pengurusan tadbir urus Mahkamah Anak Negeri di Sabah juga masih pada tahap yang kurang memuaskan dengan adanya beberapa aduan ketidakpuashatian masyarakat yang datang berurusan di beberapa buah Mahkamah Anak Negeri Daerah yang terdapat di negeri ini.

\section{Penghargaan}

Ribuan ucapan terima kasih dan penghargaan kepada Universiti Malaysia Sabah kerana telah menyediakan geran penyelidikan Skim Dana Khas SDK0086-2019 bagi memastikan penyelidikan ini Berjaya. Terima kasih.

\section{Rujukan}

Azlizan Mat Enh dan Salbiya Jamaluddin. (2020). Pentadbiran British di Sabah: Kesejahteraan anak negeri melalui penubuhan Mahkamah Anak Negeri 1884-1965 (British administration in Sabah: Well-Being of Anak Negeri through the establishment of The Native Court 18841965). Geografia-Malaysian Journal of Society and Space, 16(1).

Berita Harian. (9 Februari 2019). Isu anak negeri jangan sampai gugat perpaduan. Diakses dari https://www.bharian.com.my/rencana/komentar/2019/02 /528889/isu-anak-negeri-jangan-sampaigugat-perpaduan pada 04 Mac 2021.

Enakmen Kesalahan Jenayah Syariah (Sabah) (1995_.

Enakmen Mahkamah Anak Negeri (1992).

Enakmen Undang-Undang Keluarga Islam 1996 dan 2004 dan Kanun Keseksaan.

Husin Embi (et al.). (2004). Adat Perkawinan di Melaka dlm Abdul Latiff Abu Bakar dan Hanipah Hussin (ed.), 2004. Kepimpinan Adat Perkawinan Melayu Melaka. Melaka: Institut Seni Malaysia Melaka.

Kaedah Mahkamah Anak Negeri (Undang-Undang Adat Anak Negeri) (1995).

Kamus Dewan Edisi Keempat. (2005). Definisi Anak Negeri. Kuala Lumpur: Dewan bahasa dan pustaka.

Kamus Pelajar Edisi Kedua. (2015). Definisi Tadbir Urus. Kuala Lumpur: Dewan bahasa dan pustaka.

Kamus Undang-undang Osborn's Concise Edisi Ke-11. (2009). Definisi adat. London: Sweet and Maxwell.

Kosmo Online. (2011). Undang-undang anak negeri diamal di Sabah. Dari http://ww 1.kosmo.com.my/kosmo/content.asp? $\mathrm{y}=2011 \& \mathrm{dt}=1101 \& \mathrm{pub}=$ Kosmo\&sec=Terkini\&pg=bt_06.ht m pada 04 Mac 2021. 
Mosli Tarsat. (2009). Kerelevanan dan Prospek Jawatan Ketua Anak Negeri di Sabah: Satu Perspektif Sejarah. Sosiohumanika. Bil 2(2). M.s 227-250.

Muhammad Takari bin Jilin Syahrial dan Fadlin bin Muhammad Dja'far. (2019). Memahami Adat dan Budaya Melayu. Program Studi Etnomusikologi FIB USU dan Majelis Adat Budaya Melayu Indonesia, Medan, Indonesia.

NBCA 806. Village Administration Ordinance 5, (1913).

Ordinan Mahkamah Anak Negeri (1953).

Pertubuhan Harta Intelek Dunia. (2016). Definisi adat. Diakses dari https://www.wipo.int/export/sites/www/tk/en/resources/pdf/overview_customary_law.pdf pada $04 \mathrm{Mac} 2021$.

Pg Ismail Pg Musa Siti Zubaidah Ismail Narizan Abdur Rahman. (2018). Amalan Sogit Ke Atas Anak Negeri Sabah Beragama Islam Di Mahkamah Anak Negeri: Kajian Dari Perspektif Hukum. Jurnal Islam dan Masyarakat Kontemporari, Special Issue: Islamic Jurisprudence in Contemporary Society (18).

Pg Musa, Pg. (2020). Undang-Undang Perlanggaran Adat Di Mahkamah Anak Negeri: Konflik Pemakaiannya Terhadap Orang Islam Dalam Kerangka Perundangan Plural Di Sabah.

Rusni Hassan , Mohammad Azam Hussain \& Adnan Yusoff. (2013). Penubuhan dan Bidang Kuasa Mahkamah Muamalat di Malaysia: Isu dan Cabaran. Makalah. 25 kanun(1).

Sarabatin, Mohd Azrone (9 Februari 2019). "Isu anak negeri jangan sampai gugat perpaduan". Berita Harian. Diarkib daripada yang asal pada 23 Mac 2020. Dicapai pada 23 Mac 2020.

Sharifah Zaleha Syed Hassan. (1995). Mahkamah Anak Negeri dan pelanjutan undangundang Adat di Sabah: Satu interprestasi sosiobudaya. Dlm. Ismail Hussein, A. Aziz Deraman, \& Abd. Rahman Al-Ahmadi (pnyt.), Tamadun Melayu (hlm: 1532-1558). Kuala Lumpur: Dewan Bahasa dan Pustaka.

Soerjono Soekanto, . Hukum Adat Indonesia, Jakarta: PT Raja Grafindo Persada, 1983, him.70

Theodorson, G. A. (1964). Minority peoples in the Union of Burma. Journal of Southeast Asian History, 5(1), 1-16.

Utusan Borneo. (21 Mac 2017). Penggerak wawasan pemangkin pembangunan, menjunjung adat istiadat masyarakat. Diakses dari https://www.coursehero.com/u/file/p4jjlcc/perlanggaran-adatpantang-lara ng-perkahwinan-tuntutan-waris-perselisihan-faham/ pada 04 Mac 2021.

Wan Arfah Hamzah. (2012). A First Look At The Malaysian Legal System. Shah Alam, Selangor: Oxford Fajar Sdn. Bhd., hlm. 203-258.

Whelan, F. G. (1970). A History of Sabah. Kuala Lumpur: Macmillan and Co (S) Pte. Ltd.

Yusri Bin Pungut, Undang-undang Adat dan Perkembangan Bidangkuasa Mahkamah Anak Negeri Sabah. Kuala Lumpur: Universiti Malaya, 1998. 